\title{
Absence of prolactin gene expression in colorectal cancer
}

A J Wood, C M Thomas, K R N Baumforth, J R Flavell, K W M Scott, R H Grace, J G Williams, M R Holland, R Dunn, A G Jacobs, A Harrison, S Brun, N Plessis, P G Murray

Department of Pathology, New Cross Hospital, Wolverhampton, WV10 0QP, UK A J Wood C M Thomas K W M Scott $M$ R Holland R Dunn

A G Jacobs

Department of Surgery, New Cross Hospital, Wolverhampton R H Grace

J G Williams

School of Health Sciences, University of Wolverhampton, Wolverhampton, WV1 1DJ, UK

K R N Baumforth J R Flavell

P G Murray

Department of Histopathology, John Radcliffe Hospital, Woodstock Road, Oxford, OX2 6HE, UK A Harrison

Facultie de Pharmacie, Universitie de Montpellier I, 15

Avenue Charles Flahault 34060, Montpellier, France

S Brun

N Plessis

Correspondence to: Dr Murray. email: p.g.murray@wlv.ac.uk

Accepted for publication 9 March 1999

\begin{abstract}
Aims-Previous studies documenting hyperprolactinaemia in patients with colorectal cancer have suggested that the tumour is the source of hormone production. The aim of this study was to determine the frequency of hyperprolactinaemia in patients with colorectal cancer before, during, and after surgery, and also to determine whether prolactin is produced by these tumours.

Methods-Serum prolactin concentrations were measured in 20 patients with colorectal cancer before, during, and after surgical resection of their tumours. Samples taken during surgery included peripheral venous blood and blood taken from the main veins draining the tumour. To determine whether the tumour was responsible for the production of prolactin in these patients, paraffin wax embedded sections of tumour specimens were subjected to immunohistochemistry and western blotting using a monoclonal antibody to prolactin.

Results-Five patients (three women, two men) had preoperative prolactin concentrations above the normal reference range, although this increase was of clinical importance in only two. After surgical resection of their tumours, prolactin concentrations remained high in both patients. All 20 patients had greatly raised prolactin values at the time of surgery, irrespective of whether this was measured in peripheral blood or in blood taken from veins draining the tumour. All 20 colorectal cancer tissue samples, including those with raised preoperative and/or postoperative prolactin concentrations, were negative for prolactin staining. Frozen tissue was also available in four cases. The absence of prolactin gene expression in these four tumours was confirmed both by repeat immunohistochemistry and by western blotting. A further 50 colorectal cancer cases examined by immunohistochemistry alone were also unreactive for prolactin.

Conclusions-The results of this study suggest that serum prolactin concentrations may occasionally be raised in colorectal cancer patients, but that the tumour is not the source of hormone production. (F Clin Pathol: Mol Pathol 1999;52:135-139)
\end{abstract}

Keywords: colorectal cancer; prolactin; immunohistochemistry
Serum concentrations of prolactin, a trophic hormone produced by the pituitary gland, have been shown previously to be raised in certain groups of patients with cancer, including breast cancer and colorectal cancer. ${ }^{1-5}$ In breast cancer-for example, a relation between increasing concentrations of prolactin and deteriorating prognosis has been described, ${ }^{1}$ and a further study demonstrated an association between raised concentrations of this hormone and advanced stage (TNM stages III and IV). ${ }^{1}$

Subsequently, raised prolactin values were found in the serum of patients with colorectal cancer at the time of diagnosis. ${ }^{3}$ The same study also showed that prolactin concentrations fell after successful treatment and that the rise in prolactin showed a lead time of two to three months before recurrence. ${ }^{3}$ A second study by the same group showed that raised prolactin concentrations were also associated with a poor prognosis in patients with colorectal cancer. ${ }^{4}$

Previous studies have attempted to define the source of prolactin production in patients with colorectal cancer. In one study, prolactin gene expression was demonstrated in an undisclosed proportion of cases by immunohistochemistry ${ }^{4}$ whereas, in another, prolactin immunohistochemistry revealed positive staining in three of eight patients with colorectal cancer who had been shown previously to have raised serum concentrations at the time of diagnosis. ${ }^{5}$ The purpose of our study was to attempt to clarify whether raised prolactin concentrations in patients with colorectal cancer are the result of ectopic production by the tumour.

\section{Materials and methods}

PATIENTS

Twenty patients with a diagnosis of colorectal cancer, subsequently confirmed by histology, were recruited to our study. Of these, 11 were men and nine were women. One patient had a Dukes's A tumour, eight were Dukes's B, seven were Dukes's C, and four patients had Dukes's D tumours. Eight control patients undergoing a variety of surgical procedures, including haemorrhoidectomy, fistulostomy, and surgery for diverticular disease, but without evidence of colorectal cancer, were also included in our study.

Because prolactin concentrations are known to be affected by variations in the menstrual cycle, women were only included in our study if they were postmenopausal. Likewise, patients with evidence of pituitary, thyroid, renal, or psychiatric disease, or those taking hormonal, 
Table 1 Serum prolactin data from patients with colorectal cancer (CRC) and controls

\begin{tabular}{|c|c|c|c|c|c|c|}
\hline \multirow[b]{2}{*}{ Patient } & \multirow[b]{2}{*}{ Sex } & \multirow[b]{2}{*}{$\begin{array}{l}\text { Before } \\
\text { surgery }\end{array}$} & \multicolumn{2}{|l|}{ At surgery } & \multirow[b]{2}{*}{$\begin{array}{l}\text { After } \\
\text { surgery }\end{array}$} & \multirow[b]{2}{*}{ Dukes's staging/diagnosis } \\
\hline & & & $\begin{array}{l}\text { Peripheral } \\
\text { venous blood }\end{array}$ & $\begin{array}{l}\text { Main veins } \\
\text { draining the } \\
\text { tumour }\end{array}$ & & \\
\hline \multicolumn{7}{|l|}{$C R C$} \\
\hline 1 & $M$ & 188 & 1387 & 954 & 193 & $\mathrm{~B}$ \\
\hline 2 & $\mathrm{~F}$ & 760 & 1292 & 1318 & 872 & $\mathrm{C}$ \\
\hline 3 & $\mathrm{~F}$ & 193 & 2753 & 2877 & 235 & $\mathrm{D}$ \\
\hline 4 & M & 151 & 1501 & 1546 & 134 & $\mathrm{D}$ \\
\hline 5 & $\mathrm{~F}$ & 435 & 2646 & 2778 & 196 & $\mathrm{~B}$ \\
\hline 6 & M & 187 & 1920 & - & 198 & $\mathrm{C}$ \\
\hline 7 & $\mathrm{~F}$ & 272 & 1043 & 956 & 304 & $\mathrm{C}$ \\
\hline 8 & M & 173 & 1210 & 1201 & 145 & $\mathrm{C}$ \\
\hline 9 & M & 290 & 2461 & 1720 & 424 & $\mathrm{D}$ \\
\hline 10 & M & 79 & 642 & 606 & 263 & $\mathrm{~B}$ \\
\hline 11 & $\mathrm{~F}$ & 154 & 1249 & 1198 & 216 & B \\
\hline 12 & $\mathrm{~F}$ & 157 & 2435 & 2514 & 192 & $\mathrm{~A}$ \\
\hline 13 & $M$ & 465 & 3120 & 3204 & 269 & B \\
\hline 14 & M & 178 & 1037 & 1035 & 301 & B \\
\hline 15 & M & 177 & 2230 & 2081 & 264 & $\mathrm{C}$ \\
\hline 16 & M & 627 & 2377 & 1091 & 189 & $\mathrm{D}$ \\
\hline 17 & $\mathrm{~F}$ & 607 & 2740 & 2189 & 71 & $\mathrm{~B}$ \\
\hline 18 & $\mathrm{~F}$ & 168 & 4360 & 4070 & - & $\mathrm{C}$ \\
\hline 19 & $\mathrm{~F}$ & 1220 & 4890 & 4330 & 1221 & B \\
\hline 20 & M & 116 & 1521 & 1587 & 183 & $\mathrm{C}$ \\
\hline \multicolumn{7}{|l|}{ Control } \\
\hline 21 & $\mathrm{~F}$ & 191 & 411 & NA & 138 & Diverticular disease \\
\hline 22 & M & 236 & 1931 & NA & - & Diverticular disease \\
\hline 23 & M & 339 & 1160 & NA & 87 & Diverticular disease \\
\hline 24 & M & 147 & 1101 & NA & 201 & Diverticular disease \\
\hline 25 & M & 100 & - & NA & 130 & Haemorrhoidectomy \\
\hline 26 & M & 122 & 245 & NA & 170 & Haemorrhoidectomy \\
\hline 27 & M & 225 & 272 & NA & 243 & Haemorrhoidectomy \\
\hline 28 & $\mathrm{~F}$ & 117 & 100 & NA & 179 & Fistulostomy \\
\hline
\end{tabular}

All values are given in mIU/1. Reference ranges are: women, 65-490 mIU/1; men, 55-340 mIU/1. NA, not applicable; $F$, female; $M$, male.

opiate based, or antiemetic medicines were not included because all of these factors have been shown to affect serum prolactin concentrations. Table 1 gives full details of the patients.

SERUM PROLACTIN MEASUREMENT

Serum prolactin was measured using the DELFIA system (Wallac and Berthold Ltd, Milton Keynes, UK). This assay used time resolved fluorescence two site sandwich technology. The detection limit was $1.4 \mathrm{mIU} / 1$.

Serum prolactin was measured in the peripheral blood of all patients and controls one week before, during, and four weeks after surgery. In the case of the patients with colorectal cancer, prolactin measurements were also taken from the main veins draining the tumour at the time of surgery.

Blood samples were collected in EDTA disodium salt coated tubes. Because prolactin concentrations are subject to diurnal variation, every effort was made to ensure that measurements were taken at the same time in all patients. Therefore, blood samples were collected only between 0900 and 1200 hours preoperatively, and between 1400 and 1700 hours postoperatively. Operative samples were either collected in the morning or afternoon, but patients undergoing night-time surgery were not included.

IMMUNOHISTOCHEMISTRY

Tumour specimens from all 20 patients were available as paraffin wax embedded tissue blocks. Frozen material was also available in four cases. Sections of $4 \mu \mathrm{m}$ thickness were prepared from all paraffin wax tissue blocks and adhered to Vectabond treated (Vector laboratories, Burlingame, California, USA) microscope slides by overnight incubation at $37^{\circ} \mathrm{C}$. Cryostat sections of frozen blocks were prepared at $6 \mu \mathrm{m}$ thickness, fixed in acetone at $4^{\circ} \mathrm{C}$ for 20 minutes, and stored at $-70^{\circ} \mathrm{C}$ until required. The presence of tumour in all tissue blocks selected for immunohistochemistry was confirmed by haematoxylin and eosin staining. Before immunohistochemistry, paraffin wax embedded sections were dewaxed and transferred to phosphate buffered saline (PBS), $\mathrm{pH}$ 7.6. Cryostat sections were transferred directly to buffer. To ensure a representative spread of patients with colorectal cancer, tumours from a further 50 patients with colorectal cancer were also examined by immunohistochemistry alone.

After blocking of endogenous peroxidase activity, sections were transferred to buffer and placed in antiprolactin monoclonal antibody, NCL-PRO (Novocastra laboratories, Newcastle upon Tyne, UK), diluted $1 / 100$ in PBS buffer ( $\mathrm{pH}$ 7.6) for one hour in a humid chamber at room temperature. This antibody was effective on both paraffin wax embedded and cryostat sections, although paraffin wax sections required microwave pretreatment $(2 \times 15$ minutes, $750 \mathrm{~W}$ ). Bound primary antibody was detected using the DakoDuet system, according to the manufacturer's instructions (Dako, High Wycombe, UK). Peroxidase activity was visualised using the standard diaminobenzidine reaction. After visualisation, slides were counterstained in haematoxylin, dehydrated, cleared, and mounted in DPX. Normal human pituitary was used as a positive control in all immunohistochemical assays. Negative controls consisted of consecutive test sections in which primary antibody was either omitted or replaced with non-immune serum of the same immunoglobulin subclass.

WESTERN BLOTTING

Aliquots of $250 \mu \mathrm{l}$ of homogenised fresh tumour or normal human pituitary were sonicated for $4 \times 30$ seconds at $4^{\circ} \mathrm{C}$. After $250 \mu \mathrm{l}$ of $2 \times \operatorname{SDS}$ (sodium dodecyl sulphate) sample buffer was added to each sample, the samples were boiled for five minutes. Equal volumes of each sample $(20 \mu \mathrm{l})$ were separated on SDS $/ 10 \%$ polyacrylamide Laemmli gels. Proteins were transferred $(90 \mathrm{~V}$ for $90 \mathrm{~min}-$ utes) on to nitrocellulose membranes (Amersham Hybond-C; Amersham, Little Chalfont, UK). The synthesis of prolactin was analysed using antiserum against prolactin (NCL-PRO; Novocastra) at a 1/50 dilution. Antimouse horseradish peroxidase conjugated secondary antibody (Dako) was used at a dilution of $1 / 1000$ for detection with the enhanced chemiluminescence system (ECL; AmershamPharmacia Biotech, Rainham, UK). The standard immunodetection protocol as detailed in the ECL handbook was used. Exposure times were in the region of $30-90$ seconds.

\section{Results}

SERUM PROLACTIN MEASUREMENTS

Table 1 shows the results of serum prolactin measurements in patients with colorectal 

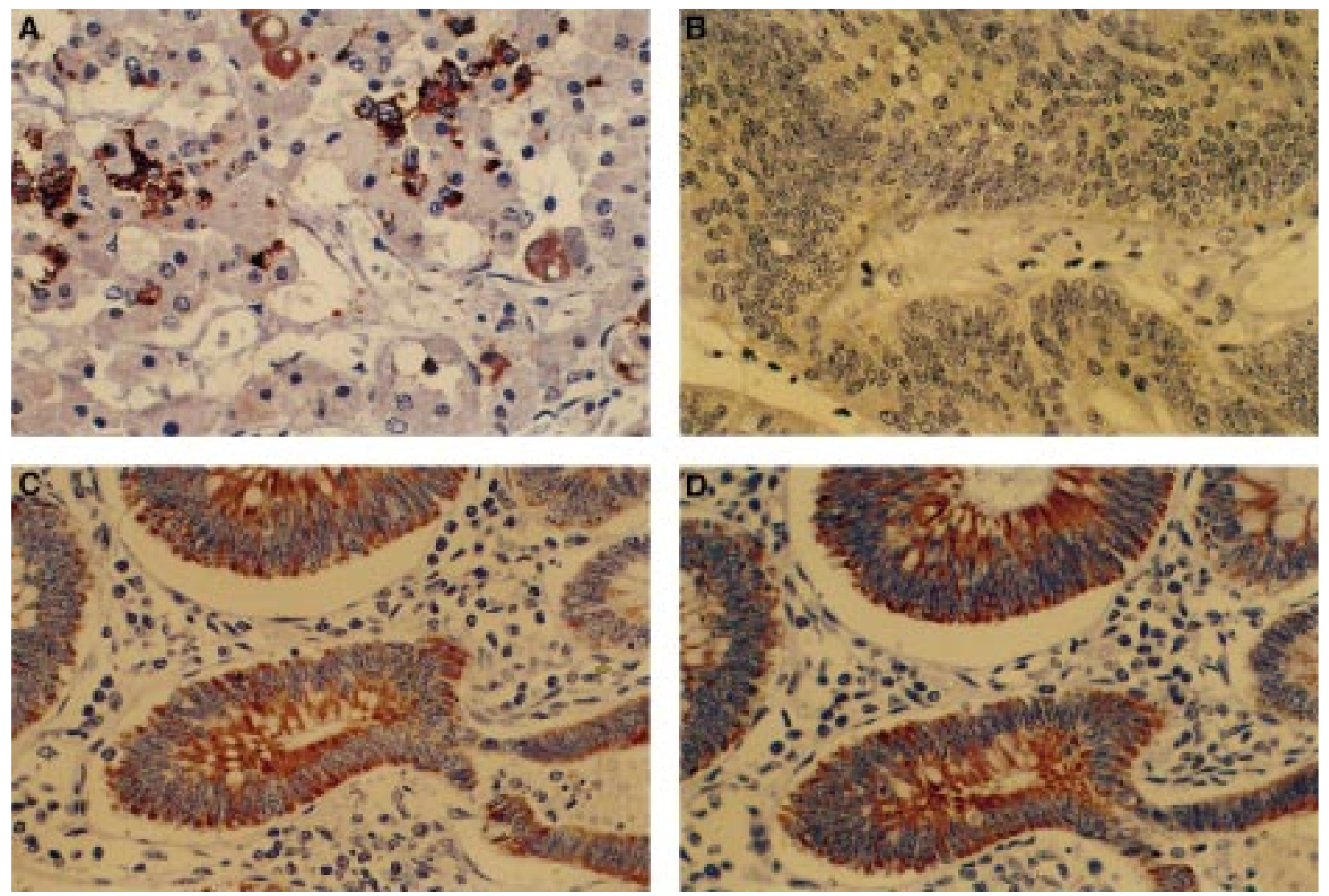

Figure 1 Immunohistochemistry for prolactin. (A) Paraffin wax embedded section of normal human pituitary showing strong staining for prolactin. (B) Absence of prolactin gene expression in colorectal cancer specimen. False positive staining for prolactin in a colorectal cancer specimen: (C) apparent staining with specific prolactin antiserum, (D) a consecutive section in which primary antibody has been omitted shows the same staining pattern. Subsequent blocking studies demonstrated that this non-specific staining was caused by the presence of endogenous biotin.

cancer and in controls. Five patients with colorectal cancer (three women, two men) had preoperative prolactin concentrations above the normal reference range. Of these, only two patients were considered to have clinically important ${ }^{67}$ rises (patients 2 and 19). After surgical resection of their tumours, prolactin concentrations remained high in both of these patients. All twenty patients with colorectal cancer had greatly raised prolactin concentrations at the time of surgery, irrespective of whether this was measured in peripheral blood or in blood taken from veins draining the tumour. There was no significant difference between prolactin concentrations measured in peripheral blood and those measured in blood taken from the main veins draining the tumour at the time of surgery.

None of the control patients had raised preoperative or postoperative concentrations of prolactin. However, operative concentrations of this hormone were greatly raised in those patients receiving surgery for diverticular disease, but not in patients undergoing haemorrhoidectomy or fistulostomy.

\section{IMMUNOHISTOCHEMISTRY}

As expected, immunohistochemistry for prolactin showed strong staining of pituitary tissue (fig 1A). However, none of the 20 colorectal tumours, including those from patients with raised preoperative and/or postoperative values, showed any evidence of prolactin stain- ing either in the tumour itself or in surrounding tissues (fig 1B). This was true for four tumour samples in which immunohistochemistry was also performed on frozen sections.

Immunohistochemistry was performed on a second series of 50 patients with colorectal cancer, all of whom were negative for prolactin immunostaining. However, high concentrations of endogenous biotin were detected in negative control sections, highlighting the importance of controls when interpreting immunohistochemical assays (fig 1C and D).

WESTERN BLOTTING

All four samples assayed by western blot analysis were negative for prolactin expression.

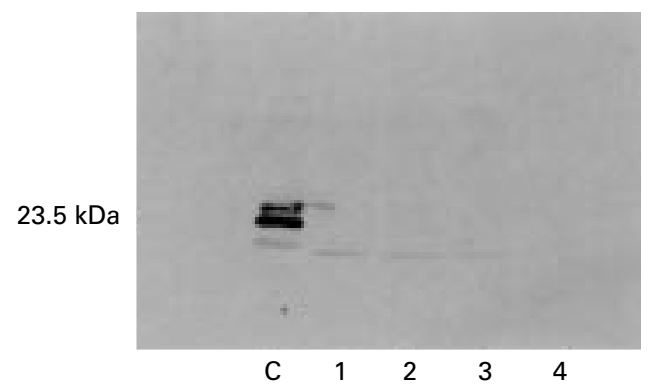

Figure 2 Western blot analysis for prolactin. Western blot analysis of tissue from four colorectal cancer tumours showed absence of prolactin gene expression (lanes 1-4), whereas normal human pituitary showed a strong band at the expected molecular weight (lane $C$ ). 
However, normal human pituitary gave a very strong band at the expected molecular weight (fig 2).

\section{Discussion}

In our study, we have shown significant increases in serum prolactin in only two of 20 patients with colorectal cancer before surgical resection of their tumours. Although an additional three patients had mild increases, the border between "normal" and "raised" prolactin is ill defined, and concentrations up to $600 \mathrm{mIU} / 1$ are generally not considered abnormal. ${ }^{6}$ Serum concentrations of this hormone remained raised in both of these patients after surgery. A combination of immunohistochemistry and western blotting failed to demonstrate the presence of prolactin in any tumour sample, including those from patiemts with raised serum concentrations. Furthermore, 50 additional colorectal cancer cases assayed for prolactin gene expression by immunohistochemistry alone were also negative. Therefore, our results suggest that hyperprolactinaemia is not a common finding in patients with colorectal cancer and that in those patients with raised concentrations the tumour is not the source of hormone production.

Previous studies have reported a much higher incidence of hyperprolactinaemia in patients with colorectal cancer. ${ }^{3-5}$ The discrepancy between the results of our study and those of other studies may be explained by a number of factors. First, some of the previous reports have included premenopausal women, or the reproductive status of the female subjects was not reported. Prolactin is greatly affected by the menstrual cycle, and the use of the same reference range for premenopausal women as for their postmenopausal counterparts may give misleading results. For this reason, premenopausal women were specifically excluded from our series. Second, in several of the previous studies there is no record of the use of specific exclusion criteria. A number of factors, including pituitary, renal, thyroid, or psychiatric disease, or treatment with hormonal, antiemetic, or opiate based medication, can dramatically alter serum prolactin concentrations. Patients with evidence of these factors were excluded from our investigation. In addition, some previous investigations have not recorded raw data, but only pooled results. In these cases it is possible that one or two very high prolactin results may have skewed the statistics.

Previous studies have also observed reductions in prolactin concentrations after successful treatment. However, in our study neither of the two patients with significant increases before surgical resection showed a reduction in prolactin concentrations after surgery, suggesting that in these two patients the tumour was not the source of their raised values. Immunohistochemistry and western blotting subsequently confirmed this. In the case of patient 2 , a possible explanation of the raised concentrations is that this patient had terminal malignant disease and had experienced at least one docu- mented ischaemic cardiac episode while in hospital. Therefore, the raised prolactin concentration in this patient may represent the stress response to severe disease. ${ }^{6}$ On the other hand, patient 19 was generally in good health and had undergone a curative resection for a Dukes's B tumour. Although there are possible explanations for this patient's raised values, including the existence of an undisclosed pituitary tumour or a heightened stress response, the precise reasons for the increases remain undetermined.

In most patients, appreciably raised prolactin concentrations were seen during surgery. This phenomenon has been noted during a variety of abdominal procedures, including hysterectomy $^{8}$ and lapararscopic cholecystectomy. ${ }^{9}$ Although physical trauma is important, it is the anaesthetic agents that are probably the main cause of the hyperprolactinaemia seen during surgery. ${ }^{8}$ A particularly potent inducer of prolactin release is the opioid analgesic, Fentanyl, ${ }^{8-10}$ and this was frequently used in the surgery described here. In the control group, patients undergoing surgery for diverticular disease, but not those receiving haemorrhoidectomy or fistulostomy procedures, also had raised prolactin concentrations during surgery. This may be explained by the fact that this latter group of patients received much shorter and less powerful anaesthetic agents than either the patients with colorectal cancer or the control patients undergoing colectomies. In addition, those patients undergoing haemorrhoidectomy or fistulostomy procedures received shorter and less extensive surgery, which in turn would lead to a reduced stress response in this group when compared with the colectomy patients.

A number of previous studies have documented increased prolactin concentrations as an adverse prognostic indicator. ${ }^{124}$ Although our study was unable to demonstrate the synthesis of prolactin by colorectal cancer tumours, prolactin release may still be important for outcome in patients with colorectal cancer. In some studies, patients with hyperprolactinaemia have been found to exhibit decreased natural killer (NK) cell activity, ${ }^{11}{ }^{12}$ whereas other groups have been unable to demonstrate differences in NK cell activity between patients with hyperprolactinaemia and age matched controls. ${ }^{13}$ However, the influence of prolactin on NK cells might be related to its concentration. ${ }^{14}{ }^{15}$ In one study, varying concentrations of prolactin produced either a dose dependent inhibition $(1,10,100$ or $250 \mathrm{ng} / \mathrm{ml})$ or stimulation $(25-50 \mathrm{ng} / \mathrm{ml})$ of resting NK cells. ${ }^{16}$ The finding that prolactin receptors are expressed on normal gastrointestinal epithelium, and also throughout the cancerous progression of colonic mucosa from adenomas to liver metastases, suggests direct effects of prolactin on the growth of colonic epithelial cells. ${ }^{17}$

In summary, the results of our study suggest that hyperprolactinaemia is rare in patients with colorectal cancer and that the tumour is unlikely to be the source of hormone production. Further work is required to establish the 
precise nature of the raised values seen in some colorectal cancer sufferers.

We are grateful to Zeneca Pharmaceuticals who kindly provided the reagents for the prolactin assays.

1 Bhatavdekar JM, Shah NG, Balar DB, et al. Plasma prolactin as an indicator of disease progression in advanced breast tin as an indicator of disease progres

2 Bhatavdekar JM, Giri DD, Shah NG, et al. Prolactin in advanced breast cancer. An Indian experience. Breast advanced breast cancer.

3 Bhatavdekar JM, Patel DD, Giri DD, et al. Comparison of plasma prolactin and CEA in monitoring patients with adenocarcinoma of the colon and rectum. $\mathrm{Br} \mathcal{F}$ Cancer 1992;66:977-80

4 Patel DD, Bhatavdekar JM, Ghosh A, et al. Plasma prolactin in patients with colorectal cancer. Cancer 1994;73:570-4.

5 Ilan Y, Sibirsky O, Livini A, et al. Plasma and tumour prolactin in colorectal cancer patients. Dig Dis Sci 1995;40: 2010-15

6 Benker G, Jaspers C, Hausler G, et al. Control of prolactin secretion. Klin Wochenschr 1990;68:1157-67.

7 Marshall WJ. Clinical chemistry, 2nd ed. New York: Gower Medical Publishing, 1992.

8 Crozier TA, Muller JE, Quittkat D, et al. Effect of anaesthesia on the cytokine responses to abdominal surgery. $\mathrm{Br} F$ Anaesth 1994;72:280-5.

9 O'Leary E, Hubbard K, Tormey W, et al. Laparoscopic cholecystectomy: haemodynamic and neuroendocrine re- sponses after pneumoperitoneum and changes in position. Br F Anaesth 1996;76:640-4.

10 Reber A, Huber PR, Ummenhofer W, et al. General anaesthesia for surgery can influence circulating melatonin during daylight hours. Acta Anaesthesiol Scand 1998;42:10506.

11 Gerli R, Rambotti P, Nicoletti I, et al. Reduced number of natural killer cells in patients with pathological hyperprolactinaemia. Clin Exp Immunol 1986;64:399-406.

12 Vidaller A, Guadarrama F, Llorente L, et al. Hyperprolactinemia inhibits natural killer (NK) cell function in vivo
and its bromocriptine treatment not only corrects it but and its bromocriptine treatment not only corrects it but
makes it more efficient. $\mathcal{F}$ Clin Immunol 1992;12:210-15.

13 Matera L, Ciccarelli E, Cesano A, et al. Natural killer activity in hyperprolactinemic patients. Immunopharmacology 1989;18:143-6.

14 Provinciali M, Di Stefano G, Stronati S, et al. Role of prolactin in the modulation of NK and LAK cell activity after short- or long-term morphine administration in neoplastic patients. Int I Immunopharmacol 1996;10:577-86.

15 Oberholtzer E, Contarini M, Veglia F, et al. Prolactin increases the susceptibility of primary leukemia cells to NK and LAK effectors. Adv Neuroimmunol 1996;6:233-47.

16 Chakraborty A, Chakraborty NG, Chattopadhyay U. Prolactin response of NK cells, but not of LAK cells, is deficient in patients with carcinoma of oral cavity and during aging. Int f Cancer 1996;66:65-9.

17 Nagano M, Chastre E, Choquet A, et al. Expression of prolactin and growth hormone receptor genes and their isoforms in the gastrointestinal tract. Am ${ }_{7}$ Physiol 190forms in the gast: 